\title{
Chapter 10 \\ Personalized Education for a Programming Course in Higher Education
}

\author{
Arturo Rojas-López \\ (D) https://orcid.org/0000-0002-2094-8283 \\ Universidad Tecnológica de Puebla, Mexico \\ Francisco José García-Peñalvo \\ (iD) https://orcid.org/0000-0001-9987-5584 \\ Universidad de Salamanca, Spain
}

\begin{abstract}
The purpose of this chapter is to present the intervention in personalized education for the Programming Methodology course in higher education. Indicators such as dropout rate, failing rate, and poor academic performance of the students of Universidad Tecnológica de Puebla (UTP) are necessary to propose strategies that improve education quality. Therefore, during the four-month periods of September-December in 2016 and 2017, the authors performed interventions with the strategy of personalized education with the objective to improve the indicators mentioned above. The four strategy elements are 1) content, 2) work methods, 3) pace and times, and 4) assessments options. The study that is presented in this chapter is original because it avoids a unique starting point for all students. The study attempts to go over what the students have in common; this is why the authors were able to stimulate each student to be in charge of their own knowledge freely and responsibly.
\end{abstract}




\section{INTRODUCTION}

In the Universidad Tecnológica de Puebla, the traditional teaching modality is face-to-face and it aims to standardize the learning of all students. In a student centered education model, personalized education contributes to recognizing the learner's individuality, so the teacher adapts the teaching methodology because each student is unique as a person and learns in different ways and speed, either face-to-face or online.

The approach of the chapter is based on the following hypothesis:

Offering personalized education to new students through different curriculum, work methods, flexible pace and time, and assessment options, will reduce the dropout rate. Personalized education, inside a learning environment in the Programming Methodology course, increase the course pass rate, and the grade average at the end of the first four-month period too.

Therefore, the chapter is organized as follows: First, we present the antecedents about the concept of personalized education as well as different approaches implemented by other researchers in different educational contexts. Second, we present the definition of the problem of the Programming Methodology course in UTP. Third, the personalized education proposal, implementation of the interventions, and the results discussion are presented. Fourth, we give suggestions for future work dealing with interventions. Finally, the conclusions evaluate the hypothesis.

\section{ANTECEDENTS}

For Bernardo et al. (2011), personalized education is an educational concept that does not belong to a particular philosophical, psychological, or pedagogical perspective, but it is a concept open to all reasonable perspectives as long as it contributes to the development of the individual.

Personalized education has been studied by several researches such as Prieto et al. (2004), Berlanga \& García-Peñalvo (2005a, 2005b, 2008), and Lerís \& Sein-Echaluce (2011) to name a few. Personalized education and its relationship with Information Technologies and Communications (ITC) offers an approach that allows "every human being to set and maintain valuable links with reality" (Calderero, 2014). For Gao (2014), personalized education will become the standard for education. However, to change from a traditional educational approach to an individualized education is not an isolated approach. The research by Hart (2016) proposed an "adaptation of education taking into account each student's particular characteristics". In the research performed by Sadovaya et al. (2016), it is mentioned that "it is necessary to develop a new model of educational strategies based on the principles of customization, dialogue, subjectivity, individual approach and complementarity". Tekin et al. (2015) framed their investigation in the web based educational systems, viewing the use of these systems as a complement "and, in some cases, as a valid alternatives for the traditional classroom teaching approach". They talked about the Massive Online Open Courses (MOOC) and highlighted the fact that these courses "are still one-size-fits-all". Therefore, they proposed a "systematic method for designing a web based customized educational model". This study stands out because it mentions three challenges when customizing instruction: "(i) students should get individualized instruction and training according to their own circumstances (for example, classes taken, preferred teaching methodologies, etc.), (ii) the best teaching and training methodology must be learned for each specific context (for example, the type of teaching materials and the order in which they are presented), (iii) the teaching and training should be adopted online in function 
of students' scores and feedback (for example, tests, questionnaires, final exams, likes/dislikes, etc.)". The work done by Laksitowening and Hasibuan (2015) also brings forth other components that "play an important role in the personalization: integrated learning structure, learning model, individualized learning environment, individualized curriculum selection and evidence based evaluation". This allowed them to propose an individualized e-Learning architecture that meets the standards for competence learning. Another approach worth considering is the research performed by Tejeda et al. (2015) that starts with educational goals from the Bolonia process and then presents a "recommendation system that delivers customized activities for the students to strengthen their individualized education". This system can be used as a guide for teachers to closely follow up each student's learning. In the Personal Mobil Technologies context, Kucirkova y Littleton (2017) claim that individualized instruction could be implemented in schools, but schools need to adapt the "concept that the children's learning needs to be adapted to the individuals' aspirations (that is, personalized) and it needs to be participative, involving the consideration of multiple perspectives (that is, pluralized)". Therefore, emphasizing the educators' important role, the authors mentioned that "the personalization and pluralization must be conceptualized as complementary forces inside the educational reform of the $21^{\text {st }}$ century". In a similar way, Humanante et al. (2015) present the conceptualization and structure of a mobile personal learning environment that puts "the student at the center of the environment".

Higher education in Mexico is not exempt from aspiring to implement personalized education, but this cannot be applied to the traditional face-to-face classes where the students cannot be taken care individually, as explained by Kostalányová (2017). Instead, the teacher must find assistance in Web technologies or e-Learning. In public education "some students may find obstacles and become bored by the massive teaching". Kostalányová explains that "instruction individualization shows the learning style, the skills, and the student's previous knowledge. In the age of society computerization, Internet, and the adequate software and hardware tools, computer-based instruction can easily become a reality". We found a success story reported by Zhao (2016) in the Chemical Engineering program, where Zhao proposes a Three Step Methodology to improve personalized education during the four-year program, not only in one subject: "(1) a professional tutorial system equipped with career counseling teachers that guides first-year students during their learning activities and also provides career counseling; (2) an experimental project: to set experimental projects open to second and third year students to choose voluntarily; (3) individualized education module: configuration of 10 different modules of individualized education for seniors to choose from". Chrysafiadi (2015) worked on a similar study to the present investigation because Chrysafiadi focuses on the teaching of the $\mathrm{C}$ programming language and reports the identification of individual needs for each student, so they can complete the training program at their own pace according to their learning skills. Chrysafiadi calls this a 'student model'. Parallel to the work of Virvou (2015), details are presented about what to model, how, and why. Barba y Chancellor (2015) consider that older students are interested in learning Computer Science due to labor competitiveness, but traditional methods are not adequate for their learning. Therefore, they take into account the life style and propose different options for a learning platform to use, the content structure, and self-guided final projects to help the students stay motivated. Other research studies that contribute to the use of personalized education are Sun et al. (2016) and Morrowy et al. (2016). The first one proposes five learning activities about visualization of geometric concepts in basic mathematics with the objective of developing independent learning skills. The second study develops algorithmic decisions that provide recommendations for scheduling customized courses based on the student's antecedents and interests. Finally, knowing the importance of personalized education, Villegas et al. (2017) develop data mining 
techniques applied to learning management systems, in particular to the system Moodle. This offers useful information to teachers with the objective of providing education adapted to the students' needs.

The new educational model for Mexico's compulsory education is called "Educate to Freedom and Creativity" (Educar para la Libertad y la Creatividad; SEP 2017). This model proposes adaptation and flexibility, elements that can be considered as part of personalized education. The model has 5 main axes:

1. Curriculum design. With a humanistic approach, gives the schools some curricular autonomy for them to adapt the educational topics to the students' specific needs and contexts.

2. The school as the center of the educational system. The school must focus on reaching the maximum level of learning of all its students.

3. Teachers' formation and developing of professional teaching skills. The teacher generates inclusive learning environments and they are able to adapt the curriculum to a particular context.

4. Inclusion and equity. The educational system is for all students and it must offer the basics so that each student has available effective opportunities for the development of all their capacities, taking into account their social and cultural individuality.

5. The educational system governance. Plurality of all parts involved in the educational process is acknowledged.

It is clear the influence of the concept that considers the student as a human being unique in their learning process and the importance of assisting them with the tools that the teacher deems as necessary. The current Educational Reform aims for the students in this country that complete each of the basic educational levels to develop their potential for the benefit of themselves and society.

\section{MAIN APPROACH OF THE CHAPTER}

\section{Problem Statement}

The computer programming teaching-learning process is not a simple activity for students and teachers. The frustration that grows from not being able to create basic software solutions for the industry or labor market during the first months of study, can become the main factor for which the students decide to dropout. Programmers are still in demand in the economic system of every country. This is why, the relevance of the acquired competencies and their applicability in the labor market reveals the success of the university educational model. Similar to other universities, the students face several factors to keep an academic college life. This is mentioned by Echegaray et al. (2017): "students' demotivation, uncertainty about the career path chosen, disinformation about the college life, or the academic programs, or the courses' curriculum, doubts about the university structure, deficiencies in their academic skills, insecurity about their own capabilities, etc."

In UTP, the common way to teach classes is one hundred percent face-to-face, with the goal of unify all students' learning based completely on the subject's curriculum that was designed previously by the General Coordination of Technological Universities at a national level. Factors such as the dropout rate, high and variable failure rate, lack of academic performance, make necessary to propose other ways to benefit education quality. In particular, the issues mentioned above are present in the first-year course 
about computer programming called Programming Methodology (PM). The PM class is taken in the first four-month period of the Advanced Technician program from the ITC division of UTP.

A new class starts every September and the Academic Services Department arranges the groups for morning and afternoon shifts. In average, there are a total of 12 groups of approximately 30 students each. The ITC division direction assigns the teachers to the groups according to the availability reported by the adjunct instructors and the tenured professors.

The indicators employed to measure the academic status of the ITC division in UTP and in particular of the above mentioned course are:

- $\quad$ Course Pass Rate (CPR - Number of students that passed the course divided by the number of students enrolled in the course),

- $\quad$ Grade ( $\mathrm{G}$ - group grade average), and

- $\quad$ Dropout rate (DR - number of students enrolled to second four-month period divided by the number of students enrolled at the beginning of first four-month period).

The median of the dropout rate (DR) at the end of the first four-month period from 2009 to 2016 was 31,13 . Since 2009 a dropout rate of 24.32 was observed and in 2014 the highest percentage of 42.24 was registered, almost half of the enrollment was lost. The median means that each year the ITC division loses just over 30 percent of the students enrolled in the first year. The median of the Programming Methodology course pass rate (CPR) in the period 2009 to 2016 was 70,67. In counterpart in the years 2009 and 2014, a low and very low percentage of accreditation was obtained, which influenced the number of students enrolled for the second semester. The student who does not credit a subject cannot enroll in the next semester. When possible, the student returned to the first semester, when the possibility ceased to exist, students chose to leave school. The median of the grades average $(\mathrm{G})$ in the same course and period of time (2009-2016) was 6,68. As you can see, the average rating is insufficient. The few students who obtain an outstanding qualification are not enough to reflect a good performance of the graduates. If from the initial course they do not have a significant learning of programming, at the end of the studies they have deficiencies of skills and knowledge. Table 1 presents the data of these indicators per each four-month period during the last 8 years. Figure 1 illustrates that DR has been increasing, while CPR has been decreasing and $\mathrm{G}$ has remained low.

\section{SOLUTIONS AND RECOMMENDATIONS}

\section{Personalized Education Proposal}

Based on the described problematic situation, during the four-month periods of September to December 2016 and September to December 2017 some interventions were performed employing personalized education as a didactic strategy with four elements as fundaments:

1. Content

2. Work methods

3. Pace and times

4. Assessment options 
Table 1. Indicators about the academic status of the PM course from 2009 to 2016

\begin{tabular}{|c|c|c|c|}
\hline \multirow{2}{*}{ Year } & \multicolumn{2}{|c|}{$\begin{array}{c}\text { Percentages } \\
\text { First four-month period }\end{array}$} & \multirow[t]{2}{*}{ Grades average } \\
\hline & Dropout & Course pass & \\
\hline 2009 & 24.32 & 77.31 & 6.78 \\
\hline 2010 & 27.81 & 74.20 & 6.67 \\
\hline 2011 & 31.13 & 70.50 & 6.64 \\
\hline 2012 & 31.14 & 71.50 & 6.69 \\
\hline 2013 & 35.20 & 65.23 & 6.18 \\
\hline 2014 & 42.24 & 58.81 & 6.31 \\
\hline 2015 & 30.30 & 70.85 & 6.81 \\
\hline 2016 & 34.00 & 68.25 & 6.75 \\
\hline Median & 31.13 & 70.67 & 6.68 \\
\hline
\end{tabular}

Figure 1. Trends of indicators about the academic status of the PM course from 2009 to 2016

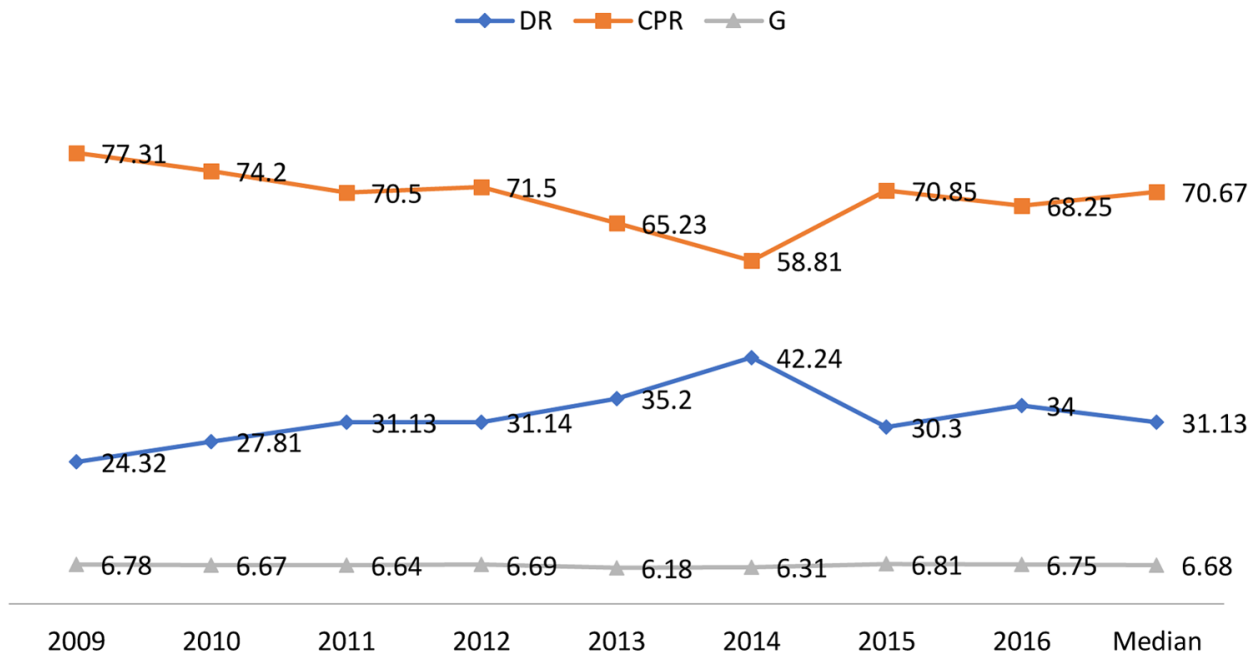

The objective was to improve the indicators of pass course rate, group grade average and to reduce the dropout rate.

The assessment of the computational thinking was a very important activity performed during the first days of each course. This allowed to offer learning environments based on the first-year students' skills. This research study is original because we did not start from a common point for all students, although we looked to take care of what they have in common inside the academic context of the course. In this way we could motivate each student to improve their own capacity for guiding their own knowledge freely and responsibly.

\section{Content}


The main topics of the PM course are described in Table 2. The personalized education strategy was supported by the use of the institutional platform Moodle, which allowed to have the topics organized in such a way that the students were able to select their learning tools. Three learning units were created and labeled as stages, with the objective of show progressive learning. Each stage focuses on one course topic and its goal is to show when the student has conquered each stage. In the course header inside the platform, there are two files. The first one contains the course framework and the second file has the definition of the concept Information Technologies, as well as the course objective and the final survey. This survey became active in a timely manner, as well as the midterm survey. Also, in each stage, there are folders labeled as Readings, Audio, and Assessments, where students find study materials in the corresponding format and text files with evaluation exercises. Lesson-type activities were added to include videos and online activities, such as crosswords and word search puzzles, which are related to the topic on hand. Finally, the platform contains forums where students answer questions about the course topics, upload assessment evidences, and make comments about their classmates' contributions. Figure 2 shows the appearance of the PM course.

\section{Work Methods}

We proposed some activities to offer an initial learning environment to the student based on the number of correct answers in the computational thinking evaluation. These activities are structured in 10 learning scenarios using three working spaces: face-to-face, semi face-to-face, and online. In the face-to-face working space, classes were conducted traditionally, this means, combining practice and theory as the course curriculum states and during the hours assigned by the program direction. In the semi face-to-face space, the technological platform Moodle was employed for adapting the learning objectives according to the number of correct answers in the computational thinking evaluation. In this format, students had a wider range of options and also tutoring days were scheduled. In the online working space, the student was able to request tutoring to solve questions or to turn in evaluation evidences.

\section{Pace and Times}

Table 2. Main topics for the Programming Methodology course

\begin{tabular}{|l|l|}
\hline \multicolumn{1}{|c|}{ Thematic unit } & \multicolumn{1}{c|}{ Topics } \\
\hline 1 & Data types \\
& Variables identifiers \\
\hline \multirow{4}{*}{3} & Arithmetic operators \\
& Logic operators \\
& Relational operators \\
& Operators hierarchy \\
& Solving expressions \\
\hline \multirow{3}{*}{} & Use of the counting and accumulator variable \\
& Selection structure (conditional) \\
& Repetition structure (cycle) \\
& Flowchart \\
& Algorithm design \\
\hline
\end{tabular}


Figure 2. Appearance of the Programming Methodology course in the Moodle platform

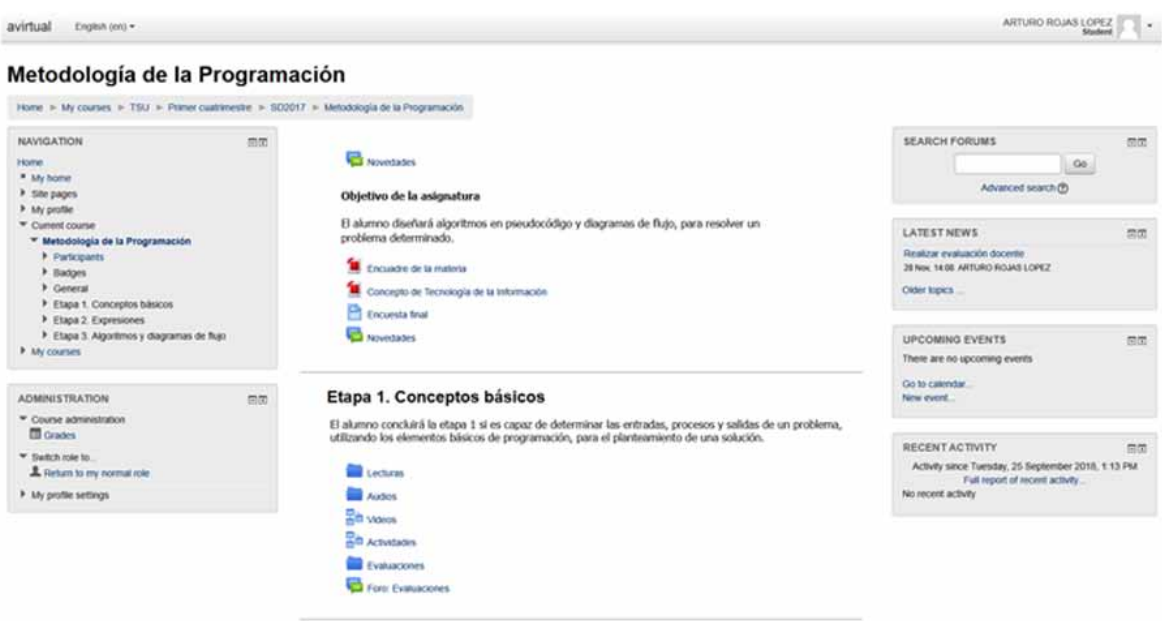

The course objective and each unit's goals were the same for all students, but each one defined their own learning pace rate. The students had the opportunity to choose what learn and the rhythm of their learning.

\section{Assessment Options}

Assessment exercises and activities were offered to the student to choose from, such as program coding, flowchart designing, or pseudocode. Depending on the work method, the evidence evaluation was face-to-face or online. There was a due date for turning in the assessment exercises and activities, but the students and teacher agreed on a revision date. Evaluation checklists for assessment items defined by the teachers academic committee were included during the intervention performed in September - December of 2017. This way the students learned about the main points to be taking into account during the evaluation. This was done with the goal of improving communication during the four-month period and not only during the revision of projects, evaluation evidence or products. Five checklists were employed during the intervention. Table 3 describes the main evaluation elements from each of the checklists.

Table 3. Evaluation indicators from checklists

\begin{tabular}{|c|l|l|}
\hline $\begin{array}{c}\text { Checklist } \\
\text { Product }\end{array}$ & \multicolumn{1}{|c|}{ Skill or knowledge to evaluate } & Corresponding Course Thematic Unit \\
\hline $\mathbf{1}$ & $\begin{array}{l}\text { Data types, correct use of variables, constants, basic arithmetic operations, } \\
\text { and input and output value identification. }\end{array}$ & 1. Basic concepts \\
\hline $\mathbf{2}$ & $\begin{array}{l}\text { Creation of algorithmic expressions, hierarchy of arithmetic, logic and } \\
\text { algebraic operators. }\end{array}$ & 2. Expressions \\
\hline $\mathbf{3}$ & Sequential and conditional control structures in algorithms. & 3. Algorithms and flowcharts \\
\hline $\mathbf{4}$ & Repetition control structures in algorithms. & 3. Algorithms and flowcharts \\
\hline $\mathbf{5}$ & Creation of methods or functions with input and/or output parameters. & 3. Algorithms and flowcharts \\
\hline
\end{tabular}




\section{Learning Scenarios}

Each subject's curriculum contains the objective of the course, and the objective of each unit, as well as the description "To Know" and "To Know How to Do" for each course topic. This is done based on Bloom's Taxonomy. We developed the learning scenarios based on the definition of the relationship between the PM course contents and the computational thinking. This is described as follows:

- Unit 1 is titled "Basic Concepts", and it has six topics. In the definition of pillar "To Know" we found the verbs Identify, Recognize and Describe, which belong to Bloom's taxonomy level two. In the definition of the pillar "To Know How to Do" we find the verb Determine also from Bloom's level two and the verb Scheme from level four, which is at the same level of Comprehend and Analyze. In consequence, we chose that these belong to the Abstraction and Breakdown skills.

- Unit 2 is titled "Expressions". In its three topics, it uses the verb Identify for the "To Know" definition, which belongs to Bloom's level two, whereas in the "Know How to Do" definition we use three times verbs from level three. One of these verbs is Apply. Therefore this will belong to the Generalization skill.

- Unit 3, "Algorithms and Flowcharts", has four topics. Verbs from cognitive level two, such as Comprehend, are present in the definition of the pillar "To Know". One verb from level five, Evaluate, is present in the definition of the pillar "Know How to Do". It also includes programming exercises using the structured programming paradigm, this is why we chose that this will be related to the Evaluation and Algorithm design skills.

Table 4 has the relationship stablished among the thematic units of the PM course and the computational thinking skills: Breakdown, Generalization, Abstraction, Algorithm design and Evaluation, as well as the name of the exercise used to evaluate each skill. Exercises that evaluate computational thinking skills were selected from two international recognized sources: the competition on computer and computational fluency in school age called UK Bebras Computational Thinking Challenge, and the talent search Computer Olympics that attempts to guide South African students with strong computational thinking skills into technical career paths. Due to the fact that the original writing is in English, a Spanish translation was made. The reason why only one exercise was selected for each of the Computational Thinking skills is the time needed to take the evaluation test, which is an average of 40 minutes. It is not intended that the students spend a lot of time solving exercises. The validation of each question is guaranteed because these are testing instruments from international sources used in competitive events, although each selected exercise is not limited to evaluating exclusively the skill for which it was selected. To evaluate computational thinking using the selected exercises, we created a Google form using UTP institutional account. We asked the students to fill out the form in the university campus to be sure that this was done.

Each learning scenario attempts to impact the PM course goals achievement in a personalized way. The description of each learning scenario is the following:

Scenario 1: Five correct answers. 
Table 4. Relationship between computational thinking skills and PM course

\begin{tabular}{|c|c|c|c|}
\hline Unit & Used Verbs & Bloom taxonomy level & $\begin{array}{l}\text { Computational thinking } \\
\text { skill / Exercise name }\end{array}$ \\
\hline \multirow{2}{*}{1 Basic concepts, 6 topics } & $\begin{array}{l}\text { To Know: } \\
\text { Identify, Recognize, and } \\
\text { Describe }\end{array}$ & 2 Comprehend & $\begin{array}{l}\text { Abstraction } \\
\text { Kangaroo }\end{array}$ \\
\hline & $\begin{array}{l}\text { To Know How To Do: } \\
\text { Scheme and Determine }\end{array}$ & 4 Analyze & $\begin{array}{l}\text { Breakdown } \\
\text { Mobiles }\end{array}$ \\
\hline \multirow{2}{*}{2 Expressions, 3 topics } & $\begin{array}{l}\text { To Know: } \\
\text { Identify }\end{array}$ & 2 Comprehend & \multirow{2}{*}{$\begin{array}{l}\text { Generalization } \\
\text { Spies }\end{array}$} \\
\hline & $\begin{array}{l}\text { To Know How To Do: } \\
\text { Locate, Solve and Convert }\end{array}$ & 3 Apply & \\
\hline \multirow{2}{*}{$\begin{array}{l}3 \text { Algorithms and flowcharts, } 4 \\
\text { topics }\end{array}$} & $\begin{array}{l}\text { To Know: } \\
\text { Recognize, Identify, and } \\
\text { Describe }\end{array}$ & 2 Comprehend & \multirow{2}{*}{$\begin{array}{l}\text { Evaluation } \\
\text { Puddle Jumping } \\
\text { Algorithm design Moving } \\
\text { beavers }\end{array}$} \\
\hline & $\begin{array}{l}\text { To Know How To Do: } \\
\text { Compare and Solve }\end{array}$ & 5 Evaluate & \\
\hline
\end{tabular}

The student has access to the online course material and he can upload practice exercises defined by the teachers committee. The student can take the evaluation of each thematic unit fifteen days after the beginning of four-month period using the Moodle technological platform. If a student gets approved results, the student passes the course. Otherwise, a face-to-face revision meeting is scheduled between the student and the teacher where the exercises are reviewed and questions are answered. Then, the student may decide to get new practice exercises for evaluation or to take the online course.

Scenario 2: Algorithm design exercise incorrect.

In this case the student will strengthen the algorithm design ability with exercises in the platform Moodle, and take full course evaluations one month after the beginning of the four-month period. Based on this, the student passes the course or chooses to take the online course.

Scenario 3: Evaluation exercise incorrect.

The student will strengthen the sequential, decision, and repetition structures skills performing coding exercises that solve a problem using control structures. Also, tutoring sessions for these topics and laboratory practices will be scheduled. One month after the beginning of the four-month period the student will take the full course evaluations. Based on this, the student passes the course or chooses to take the online course.

Scenario 4: Algorithm design and Evaluation exercises incorrect.

The student has access to the online course material and to do practice activities for solving the structured programming exercises proposed by the teachers committee. Each student may schedule three face-to-face tutoring sessions with their teacher and one month after the beginning of the four-month 
period the student can request the evaluation of online tests and practice exercises. If he or she gets grades good enough to pass the tests and exercises, will pass also the course. Otherwise he or she can choose to take the course online or semi face-to-face.

Scenario 5: Generalization exercise incorrect.

The student will strengthen the skills related to the arithmetic, logical and relational expression evaluation taking into account the operators' hierarchy by coding exercises that involve operations computation and conditionals. One month after the beginning of the four-month period the student will that the full course evaluations. Based on this, the student passes the course or chooses to take the online course.

Scenario 6: Algorithm design, Evaluation and Generalization exercises incorrect.

The student may work in a semi face-to-face environment, where course material and activities will be made accessible in a timely manner based on the course curriculum and the didactic planning done by the teachers committee. The student may request tutoring sessions with the course teacher, and do the practices and take the tests in the times defined by the teachers committee.

Scenario 7: Abstraction or Breakdown exercises correct.

The student has the basic skills necessary in particular for programming learning. Therefore, they may choose a semi face-to-face environment, but with regular personal face-to-face tutoring sessions during laboratory practices. The student will do departmental evaluations and assessment practice exercises to develop those skills that need improvement, this is, Generalization and Algorithm design.

Scenario 8: All exercises incorrect.

It may happen that the student does not have the required skills to be part of the program. In this case, they will find difficulty during thematic unit three when trying to understand control structures and algorithm design. We recommend to have a meeting with the teacher, directive, and student, to value the student's vocational profile. It is very likely that a face-to-face course is the best option for the student.

Scenario 9: Breakdown and Abstraction exercises incorrect.

In this case, it is recommended that the student work in a semi face-to-face environment. He or she should select a day in a week to do a laboratory practice once a week.

Scenario 10: Design algorithm and Evaluation exercises correct.

The student may study online the first two thematic units, and work in a semi face-to-face environment after five weeks. 


\section{Interventions}

The data about course pass rate, dropout rate and grade average from 2009 to 2016 comprises a total of 3659 students that took the PM course in similar conditions as the control groups that had the interventions. The control groups during the interventions were characterized as face-to-face classes inside a classroom or laboratory, did not use the Moodle institutional platform and evaluations were conducted at two times as indicated by the respective teachers committee. Evaluations could be done by a written exam, laboratory practice, homework assignments, and final project. In general, the course teacher chose to use the Java or C\# programming language.

For the intervention in the four-month period September - December of 2016, the groups 1A, 1B, $1 \mathrm{E}, 1 \mathrm{~F}$ and $1 \mathrm{G}$ helped to compare results against the experimental groups, because their teachers shared the student grades. For the intervention in the four-month September - December of 2017, none of the groups outside the experimental groups shared grades.

The experimental groups were those that had a researcher as teacher. For the PM course, the first intervention was carried out in the groups 1C and 1D with 32 and 33 students in each group, and the second intervention in the groups $1 \mathrm{~B}$ and $1 \mathrm{H}$ with 35 students in each group.

\section{Results}

\section{Intervention During September - December of 2016}

Table 5 shows the number of students that participated in each scenario of the 2 experimental groups, after the evaluation of computational thinking, as well as the most remarkable group agreement according to the learning scenario. Although the same scenarios were present in the two groups (except scenario 1 for the group 1D) the variation in the quantities showed the individuality of the students and the justification for personalizing their learning environment. That is, this was an indication of the diversity of knowledge and skills with which the students started the University program.

Table 5. Number of students per scenario during the intervention September to December of 2016

\begin{tabular}{|c|c|c|l|}
\hline \multirow{4}{*}{ Group } & Scenario & $\begin{array}{c}\text { Number of } \\
\text { students }\end{array}$ & \multicolumn{1}{|c|}{ Observations } \\
\hline \multirow{3}{*}{$1 \mathrm{C}$} & 5 & 6 & October $11^{\text {th }}$ was the date for revision of assignments. \\
\cline { 2 - 4 } & 7 & 5 & Friday was the day chosen for laboratory practice. \\
\cline { 2 - 4 } & 9 & 8 & Thursday was the day chosen for laboratory practice. \\
\cline { 2 - 4 } $1 \mathrm{D}$ & 10 & 13 & Stage 3 started on October $18^{\text {th }}$. \\
\hline \multirow{3}{*}{} & 1 & 3 & Revision of course evidences on September $30^{\text {th }}$. \\
\cline { 2 - 4 } & 5 & 2 & Revision of course evidences on October $7^{\text {th }}$. \\
\cline { 2 - 4 } & 7 & 10 & Monday was the day chosen for laboratory practice. \\
\cline { 2 - 4 } & 9 & 14 & Students selected the day for tutoring sessions. \\
\cline { 2 - 4 } & 10 & 4 & Stage 3 started on October $17^{\text {th }}$. \\
\hline
\end{tabular}


Table 6 shows the number of students that passed the course either in ordinary or extraordinary periods, as well as the number of students that did not pass the course or dropped out. Passing grade values are 8 (C - Satisfactory), 9 (B - Outstanding), or 10 (A - Autonomous). Figure 3 shows that there is not a big difference between the approved students in the control and experimental groups, except with the groups $\mathrm{E}$ and $\mathrm{F}$. As well as, the average of the control groups against the experimental ones. The number of students approved in extraordinary is significant in the experimental groups, except with the group G. Finally, it also shows that the school drop does not decrease in comparison with the average of the control groups.

The results per learning scenario were as follow:

Table 6. Results at the end of the four-month period September to December of 2016

\begin{tabular}{|l|c|c|c|c|c|c|}
\hline \multirow{2}{*}{ Group } & \multicolumn{3}{|c|}{ Ordinary } & \multirow{2}{*}{ Extraordinary } & & \multirow{2}{*}{ Dropout } \\
\cline { 2 - 4 } \cline { 3 - 4 } & C & B & A & & Pass & \\
\hline A & 10 & 5 & 6 & 5 & 26 & 8 \\
\hline B & 8 & 4 & 5 & 8 & 25 & 8 \\
\hline C & 2 & 3 & 5 & 18 & 25 & 4 \\
\hline D & 1 & 3 & 2 & 19 & 12 & 8 \\
\hline E & 0 & 1 & 2 & 9 & 13 & 21 \\
\hline F & 3 & 1 & 1 & 8 & 26 & 20 \\
\hline G & 0 & 1 & 6 & 19 & & 6 \\
\hline
\end{tabular}

Figure 3. Results of the intervention September - December 2016

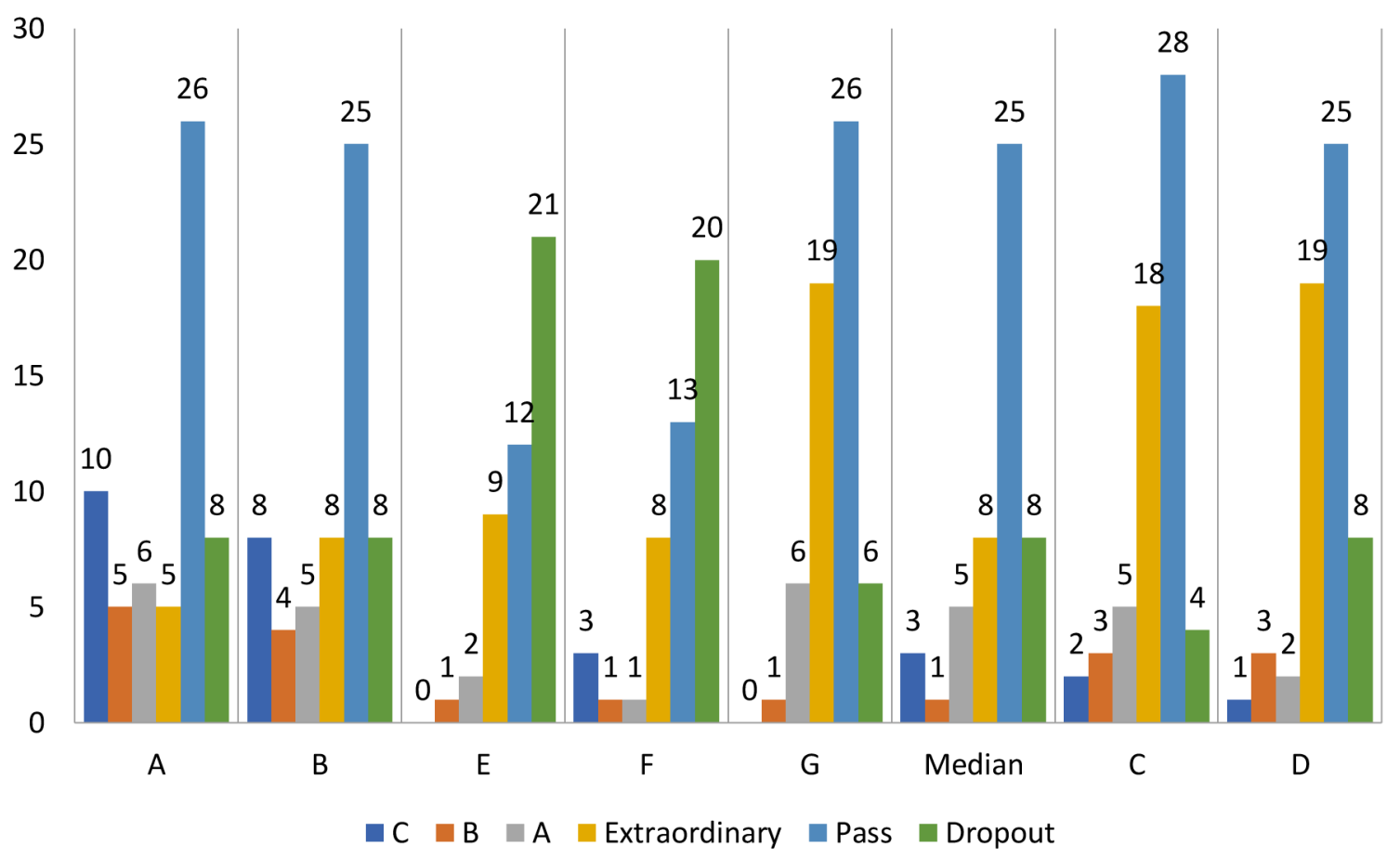


Scenario 1: From the group 1D the two students with Autonomous grade (A) were disciplined when using an online learning environment, attended tutoring sessions, and presented the evidence of evaluation on the due date, obtaining a passing grade. The third student obtained Outstanding grade (B) because the delivery of evaluation evidence was $90 \%$ of what was agreed, but sufficient to accredit the course.

Scenario 5: The 8 students from both groups chose the semi face-to-face modality one month after the start of the four-month period. Laboratory practice was scheduled once per week, but despite the fact that the study material was online, it was not used, since no progress was evident in the laboratory. Because of this, laboratory practice had to start with a theoretical explanation and then do the programming. Three students obtained Outstanding (B), two Satisfactory (C), and three accredited in the extraordinary period.

Scenario 7: The 15 students of the two groups chose the semi-face-to-face space, although they set one day for classroom lectures and one day for practice. The evaluation was done based on the time stated in the course curriculum and the exercises determined by the teachers committee. One student obtained Satisfactory (C), 2 Outstanding (B), 5 Autonomous (A) and 7 passed the course in extraordinary.

Scenario 9: The students that studied the online material had a better use of the laboratory time. 13 passed the course in the extraordinary period and 9 were dropouts.

Scenario 10: The students worked the first two thematic units online without problem. However, for the last unit, in spite of transitioning to a semi face-to-face environment, they did not keep the same performance of autonomy. Algorithm design and coding were the main topics discussed during the extra laboratory hours requested that were not initially considered in the scenario. Of the 17 students, 14 accredited in extraordinary and 3 were dropouts.

Figure 4 shows the results of approval and dropouts by scenario. Highlights the number of students who pass in extraordinary mainly in scenarios 7, 9 and 10. School dropouts were obtained in scenarios 9 and 10.

\section{Intervention During September - December of 2017}

Again, a diversity of scenarios were offered to students after the computational thinking evaluation, which confirms the students' individuality and the importance of personalizing their learning environment. Table 7 shows the number of students per scenario in each experimental group, in addition to initial observations of the intervention. It should be noted that some students did not show up at the beginning of the course, this is why 5 of the 35 students in group 1B and 2 of the 35 students in group $1 \mathrm{H}$ are not included.

During this intervention, an earthquake of magnitude 7.1 was registered on September $19^{\text {th }}, 12$ days after beginning the course. The offering of scenarios was fortunately carried out, as well as the revisions of planned activities, but the classroom activities were prioritized once the classes resumed 20 days after the earthquake. The natural disaster caused the server of the Moodle platform to shut down and the service was not resumed until local authorities allowed access to the administrator of the platform. The majority of the students were able to download course content and checklists of the first three products. The learning process was interrupted only for the students in face-to-face mode, although communica- 
Figure 4. Results by scenarios in the experimental groups September - December 2016

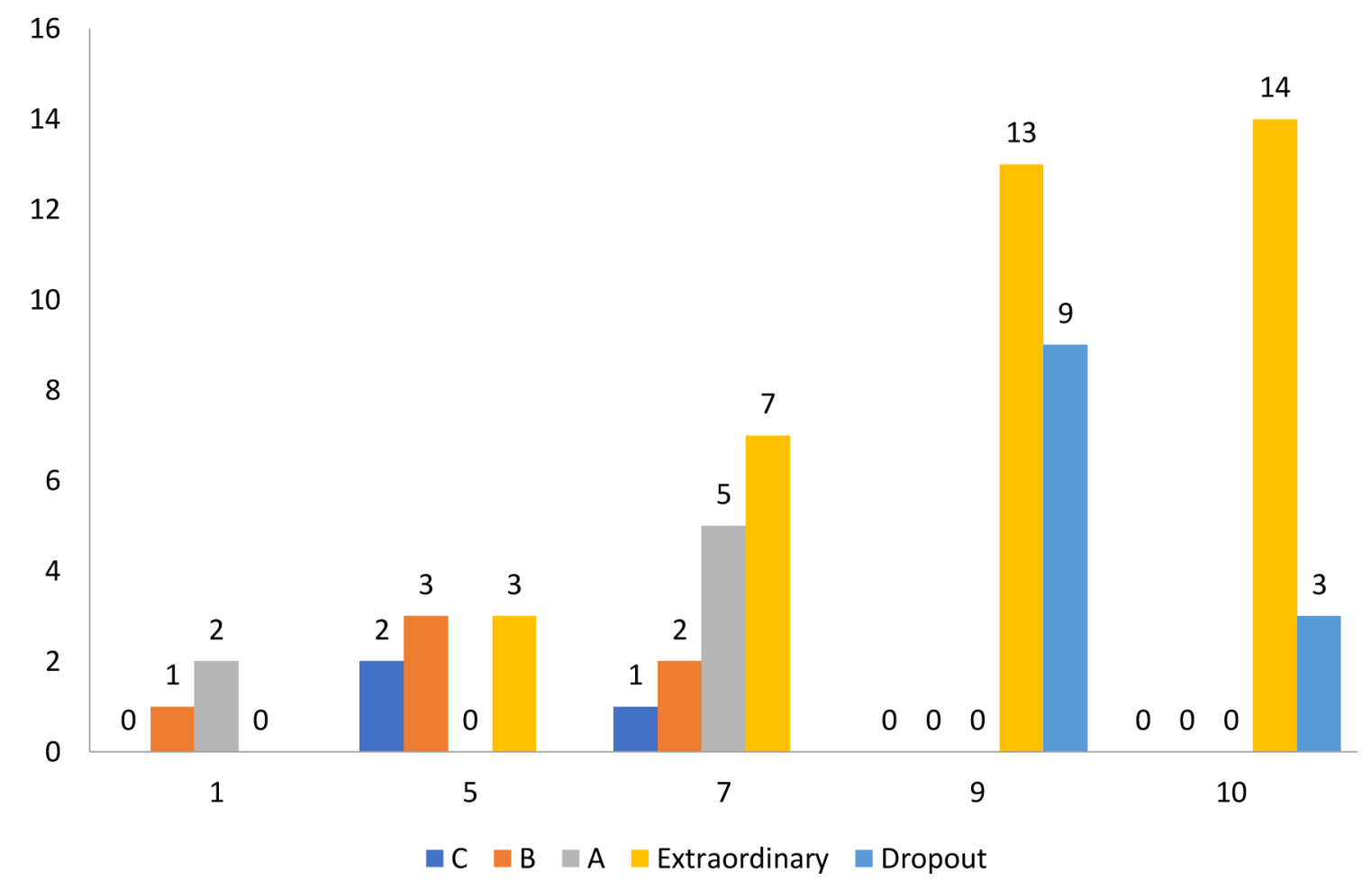

tion was maintained through the social network Facebook. Table 8 shows evaluation results by group at the end of the four-month period.

When observing the results of Figure 5 of the students who passed the course in the two experimental groups, there are 13 with Autonomous grade (A), more than in the first intervention. This can be explained by their ability to self-regulate their learning after the occurrence of the earthquake. 15 students obtained the minimum Satisfactory grade (C) and 8 got Outstanding (B), that is, 36 students of 48 passed the course through the learning scenario in the ordinary period, and also a total of 12 accredited in the extraordinary period. Before result is an indication of the importance to look for balance between faceto-face and semi face-to-face spaces. Had it not been due to the server failure, better results would have been obtained in the final evaluations. Students did not have virtual environment and the benefits offered by the Moodle platform when classes were cancelled. The workload of the evaluation process increased by the use of the checklists, but this situation provided a clarification of the elements of accreditation which was an improvement compared with the previous intervention.

\section{Discussion}

For the four-month period September to December of 2016, the dropout percentage was 24,24 for group 1C and 27,27 for group 1D, which are 6,89 and 3,86 percent less than the median of the last 8 years $(31,13)$. The pass course percentage was 81,82 for $1 \mathrm{C}$ and 72,73 for $1 \mathrm{D}$, which are 11,14 and 2,05 percent higher 
Table 7. Number of students per scenario during intervention in September to December of 2017

\begin{tabular}{|c|c|c|c|}
\hline Group & Scenario & Students & Observations \\
\hline \multirow{7}{*}{$\begin{array}{l}1 \mathbf{B} \\
30\end{array}$} & 1 & 4 & $\begin{array}{l}\text { More students with } 5 \text { exercises correct. Friday October } 13^{\text {th }} \text { was the date set for evaluation } \\
\text { products revision. }\end{array}$ \\
\hline & 3 & 1 & The student chose scenario 10 due to the number of classmates that belong to this scenario. \\
\hline & 5 & 2 & Revision of course evidences on October $2^{\text {nd }}$. \\
\hline & 7 & 6 & Two class hours per week are used for laboratory practice. \\
\hline & 8 & 2 & $\begin{array}{l}\text { The students mentioned that they chose correctly their career path and they join scenario } \\
10 .\end{array}$ \\
\hline & 9 & 3 & Two class hours per week are used for laboratory practice. \\
\hline & 10 & 12 & The highest number of students. The semi face-to-face environment starts on October $9^{\text {th }}$. \\
\hline \multirow{6}{*}{$\begin{array}{l}1 \mathbf{H} \\
33\end{array}$} & 5 & 1 & This student joins the scenario 7 group. \\
\hline & 6 & 1 & This student joins the scenario 7 group. \\
\hline & 7 & 14 & $\begin{array}{l}\text { They chose a semi face-to-face environment but attach importance to face-to-face format } \\
\text { requesting } 4 \text { hours of classroom time. }\end{array}$ \\
\hline & 9 & 12 & They work in semi face-to-face environment. \\
\hline & 10 & 2 & The semi face-to-face environment starts on October $9^{\text {th }}$. \\
\hline & 8 & 3 & The students mentioned that they chose correctly their career path and they join scenario 7 . \\
\hline
\end{tabular}

Table 8. Evaluation results during intervention in September to December of 2017

\begin{tabular}{|l|c|c|}
\hline & $1 B$ & 1 H \\
\hline Grade & \multicolumn{2}{|c|}{ Number of students } \\
\hline Autonomous (A) & 8 & 5 \\
\hline Outstanding (B) & 6 & 2 \\
\hline Satisfactory (C) & 5 & 10 \\
\hline Extraordinary & 4 & 8 \\
\hline Dropout & 12 & 10 \\
\hline
\end{tabular}

than the last 8 years median (70,67). The grade average of the PM course was 7,12 for students in group $1 \mathrm{C}$ and 6,81 for group $1 \mathrm{D}$, which is 0,43 and 0,13 higher compared to the last 8 years median $(6,68)$.

The number of students that passed the course in the experimental groups is similar to the control groups, as well as the number of students who did not pass or dropped out, except very drastically in groups $1 \mathrm{E}$ and $1 \mathrm{~F}$. It is worth noting that the number of students who passed in the extraordinary period is higher in the experimental groups. For the group $1 \mathrm{G}$, those who passed the course in extraordinary period were promoted by the direction of the program after the four-month period had ended. The previous action does not provide a correct comparison with the research between that control group and the experimental ones.

Therefore, the way of presenting the contents of the subject after evaluating computational thinking skills represented a novelty for the personalized education strategy and may help in similar contexts worldwide. 
Figure 5. Results of experimental groups September - December 2017

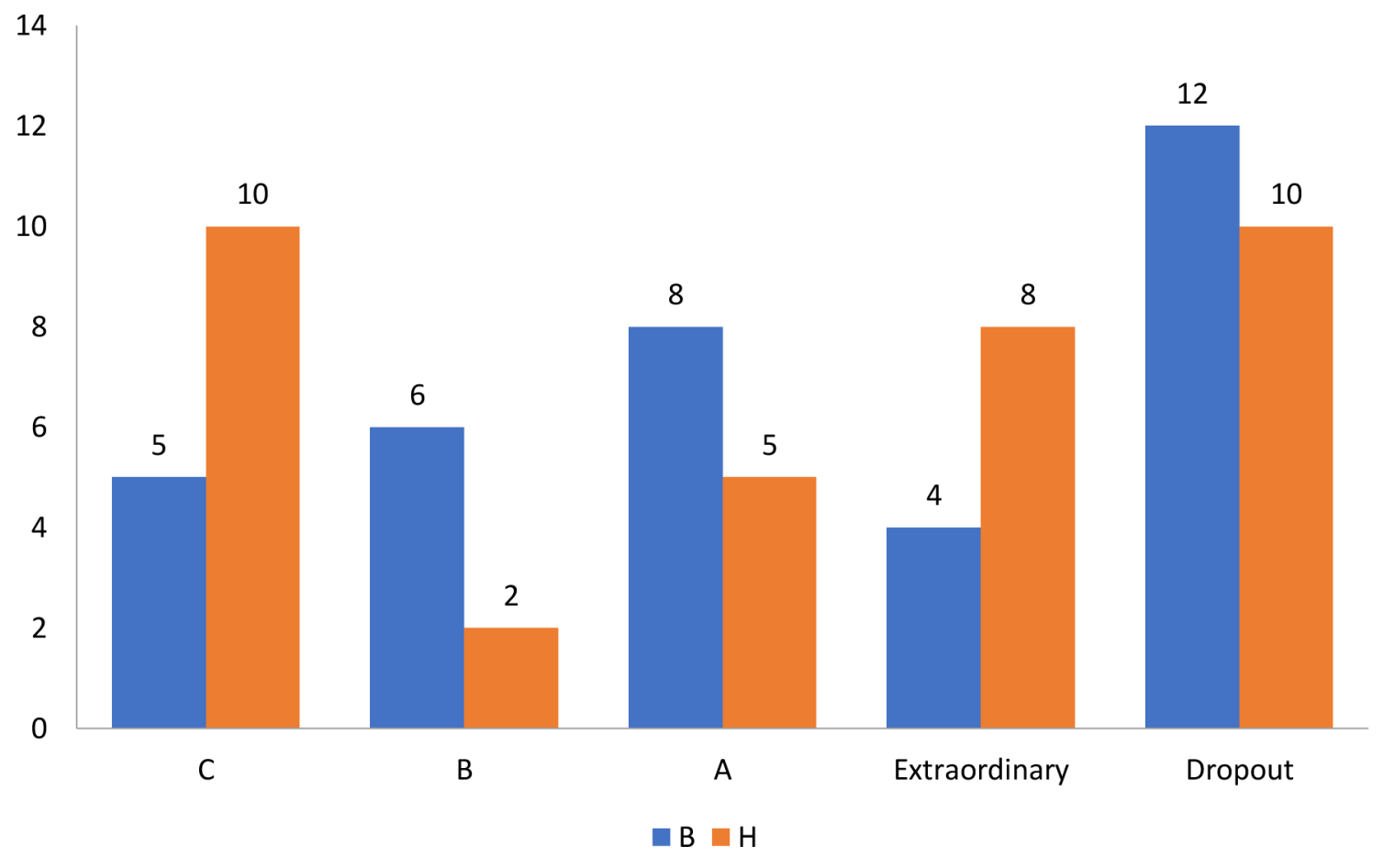

For the four-month period of September to December of 2017, there was a high number of students who no longer showed up when activities resumed after the magnitude 7.1 earthquake. This prevented an improvement regarding the percentage of dropout and accreditation, consequently, the grade average is also lower than the median of the last 8 years. In the absence of control groups, a comparative analysis is lacking but despite this, experience is considered. Table 9 presents the information discussed above.

At midterm September - December of 2016, students were asked to voluntarily take a survey. The questions are shown in Table 10, as well as the percentage values of the answers. 24 of the 65 students participated in this survey. Figure 6 shows that the success of the proposal lies in the acceptance of the strategy, the students have clear the objective of the course and the use of the platform.

Halfway through the four-month period mentioned above, $75 \%$ of the respondents are happy with their learning space, $66.7 \%$ understand the learning objectives of the course, $83.3 \%$ use the Moodle platform and the resources contained without difficulty. It is worth noting that $83.3 \%$ of the students use the platform activities. Finally, the personalized education strategy indicates that the face-to-face space is the best option for the respondents.

At the end of the four-month period another voluntary survey was conducted. 15 students responded and the questions and values are shown in Table 11. The first part asked about the knowledge learned, then we asked some questions about the learning environment, as well as questions about the initial evaluation of computational thinking that went over the skills of Decomposition, Generalization, Abstraction, Algorithmic Design, and Evaluation. Finally, recommendations for students of future classes were requested. 
Table 9. Comparative table about dropout rate, pass rate and grade average of the last 8 years and the interventions of this study

\begin{tabular}{|c|c|c|c|}
\hline \multirow[t]{2}{*}{ Year } & \multicolumn{2}{|c|}{$\begin{array}{c}\text { Percentages } \\
\text { First four-month period } \\
\end{array}$} & \multirow[t]{2}{*}{ Grades average } \\
\hline & Dropout & Pass & \\
\hline 2009 & 24.32 & 77.31 & 6.78 \\
\hline 2010 & 27.81 & 74.20 & 6.67 \\
\hline 2011 & 31.13 & 70.50 & 6.64 \\
\hline 2012 & 31.14 & 71.50 & 6.69 \\
\hline 2013 & 35.20 & 65.23 & 6.18 \\
\hline 2014 & 42.24 & 58.81 & 6.31 \\
\hline 2015 & 30.30 & 70.85 & 6.81 \\
\hline 2016 & 34.00 & 68.25 & 6.75 \\
\hline Median & 31.13 & 70.67 & 6.68 \\
\hline $1 \mathrm{C} 2016$ & 24.24 & 81.82 & 7.12 \\
\hline 1D 2016 & 27.27 & 72.73 & 6.81 \\
\hline 1B 2017 & 34.29 & 65.71 & 5.54 \\
\hline 1H 2017 & 28.57 & 71.43 & 4.94 \\
\hline
\end{tabular}

Table 10. Midterm survey in four-month period September to December of 2016

\begin{tabular}{|c|c|}
\hline Question & Answers options \\
\hline $\begin{array}{l}\text { Does the work space seem appropriate according to your learning } \\
\text { expectative? }\end{array}$ & $\begin{array}{l}\text { Yes }-75 \% \\
\text { No }-25 \%\end{array}$ \\
\hline Do you know the course knowledge goals? & $\begin{array}{l}\text { Yes }-66.7 \% \\
\text { No }-33.3 \%\end{array}$ \\
\hline $\begin{array}{l}\text { Do you feel lost when using the technological platform, do you not } \\
\text { know what to do and what for? }\end{array}$ & $\begin{array}{l}\text { Yes }-16.7 \% \\
\text { No }-83.3 \%\end{array}$ \\
\hline Among the platform resources, which did you use? & $\begin{array}{l}\text { Audio }-45.8 \% \\
\text { Video }-54.2 \% \\
\text { Readings }-70.8 \% \\
\text { Activities }-83.3 \%\end{array}$ \\
\hline $\begin{array}{l}\text { Do you agree with your learning environment? And, What action do } \\
\text { you suggest to boost your learning? }\end{array}$ & $\begin{array}{l}\text { Regarding the learning environment: } \\
\text { Agree }-54.2 \% \\
\text { Disagree }-16.6 \% \\
\text { No comment }-29.2 \% \\
\text { Regarding suggestions: } \\
\text { Face-to-face environment }-37.5 \% \\
\text { More exercises }-12.5 \% \\
\text { Correct content }-29.2 \% \\
\text { No comment }-20.8 \%\end{array}$ \\
\hline
\end{tabular}


Figure 6. Percentages that favor the proposal made

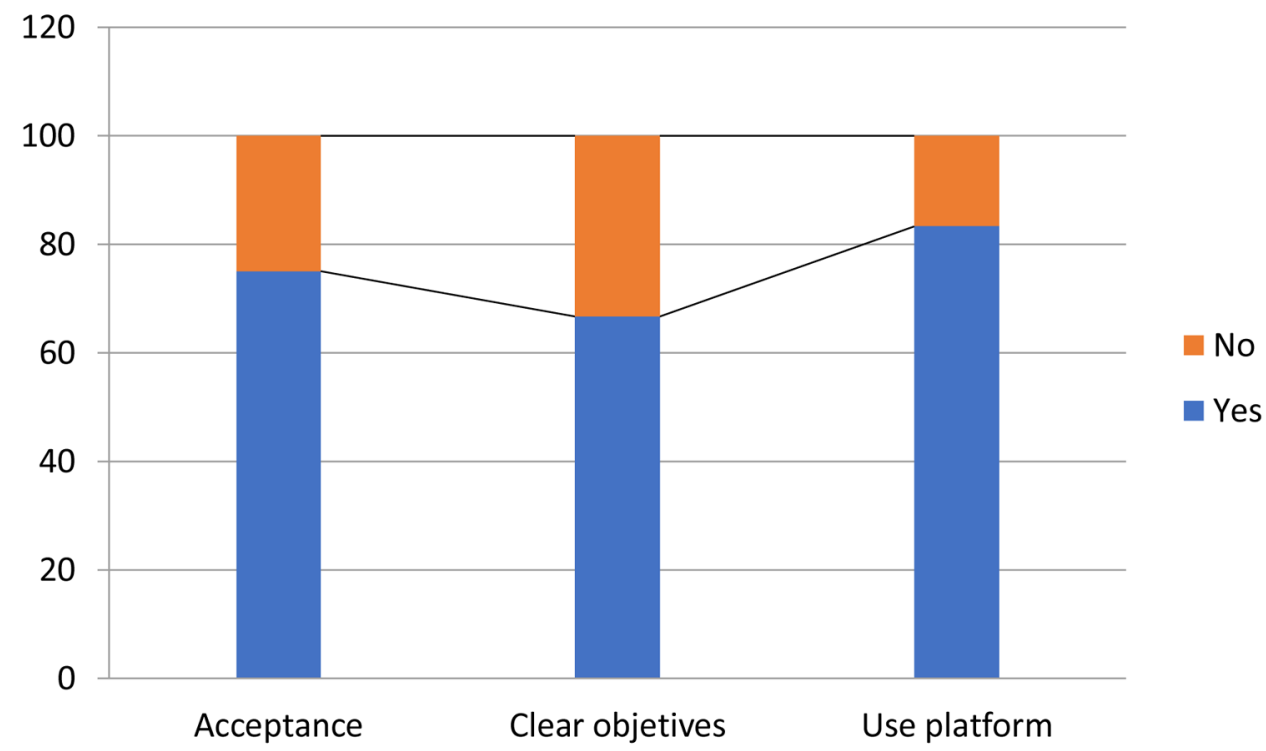

The evaluation of computational thinking skills at the beginning of the four-month period was approved by $73.3 \%$ of the survey respondents, and the acceptance of the learning environment was $86.7 \%$. This is a very relevant result that justifies the proposal and its intervention in the classroom. Although the majority of students accredited during the extraordinary period, the learning scenarios were accepted highlighting the use of activities, readings, and visual content in the Moodle platform.

The midterm survey of the four-month period from September to December 2017 could not be carried out due to the earthquake of September $19^{\text {th }}$. Only 10 students from group 1B took the final survey and the information is presented in Table 12. It should be noted that among the respondents one got the 5 exercises correct, therefore their autonomy was higher, and the rest of the respondents worked in the semi face-to-face environment. Most of the students said they were familiar with the concepts learned in the course. The concept that students said they were less familiar with, was the selection structure concept (use of conditionals) for which only $60.0 \%$ of the students claimed they were familiar with. Regarding the other questions, the responses were very favorable and satisfactory. $100 \%$ of the students surveyed accepted the learning environment, as well as, the evaluation of computational thinking to determine this scenario.

\section{FUTURE RESEARCH DIRECTIONS}

Based on the obtained results, we can conclude that promoting autonomous learning is one of the students' area of opportunity because we observed these three common behaviors:

- Reminders about study activities were necessary,

- The assignments due dates were generally determined by the teacher, and

- Students limit their knowledge source to the material provided by the University. 
Table 11. End of the four-month period survey during the intervention in September to December of 2016

\begin{tabular}{|c|c|}
\hline Question & Answers and percentages \\
\hline \multicolumn{2}{|l|}{ Select the concepts you are familiar with: } \\
\hline Data types & $73.3 \%$ \\
\hline Arithmetic operators & $60 \%$ \\
\hline Variable identification creation & $66.7 \%$ \\
\hline Logical operators & $73.3 \%$ \\
\hline Relational operators & $66.7 \%$ \\
\hline Operators hierarchy & $73.3 \%$ \\
\hline Solving arithmetic, logic and relational expressions & $66.7 \%$ \\
\hline Use of the counter and accumulator variable & $73.3 \%$ \\
\hline Selection structure & $26.7 \%$ \\
\hline Repetition structure & $73.3 \%$ \\
\hline Algorithm creation and definition & $66.7 \%$ \\
\hline $\begin{array}{l}\text { Did the learning environment was appropriate to develop the course } \\
\text { competences? }\end{array}$ & $\begin{array}{l}\text { Yes }-86.7 \% \\
\text { No }-13.3 \%\end{array}$ \\
\hline $\begin{array}{l}\text { Do you think that evaluating your skills at the beginning of the four- } \\
\text { month period was the right activity to do in order to determine the best } \\
\text { learning environment? }\end{array}$ & $\begin{array}{l}\text { Yes }-73.3 \% \\
\text { No }-26.7 \%\end{array}$ \\
\hline $\begin{array}{l}\text { What suggestion do you have for future classes regarding the way to } \\
\text { learn the course content? }\end{array}$ & $\begin{array}{l}\text { Study }-46.6 \% \\
\text { Face-to-face }-20 \% \\
\text { None }-20 \% \\
\text { Same thing for everyone }-6.7 \% \\
\text { I liked it and I was motivated to investigate and learn } \\
\text { more by own }-6.7 \%\end{array}$ \\
\hline
\end{tabular}

The lack of a study discipline made it difficult to take control of their educational process, as indicated by the high number of students who passed the course during the extraordinary period of scenarios 9 and 10 compared to the number of students who passed during the extraordinary period in the control groups which had face-to-face class. Most of the students indicated that they are comfortable in a faceto-face space where the teacher is the only responsible to carry out the didactic strategies for the group. However, there exists an enthusiasm for the semi face-to-face instruction, but it is needed a more precise planning and activities monitoring so the students experiment external control of their educational process. There is still a lot of research work to be done in order to express that with the personalized education proposal school drop-out is prevented in the programming course. The investigator will have to determine if there are other factors or circumstances that were omitted in the intervention performed. Finally, at the end of future interventions increase the number of students who respond to the survey.

We definitely propose the following actions for future interventions of the personalized education strategy:

1. Perform the computational thinking evaluation, using the activities previously selected, preferably during the first three days of the four-month period in those groups where the didactic strategy will be carried out. 
Personalized Education for a Programming Course in Higher Education

Table 12. End of the four-month period survey during the intervention in September to December of 2017

\begin{tabular}{|l|l|}
\hline \multicolumn{1}{|c|}{ Question } & \multicolumn{1}{|c|}{ Answers and percentages } \\
\hline Select the concepts you are familiar with: & $90 \%$ \\
\hline Data types & $90 \%$ \\
\hline Arithmetic operators & $100 \%$ \\
\hline Variable identification creation & $90 \%$ \\
\hline Logical operators & $80 \%$ \\
\hline Relational operators & $90 \%$ \\
\hline Operators hierarchy & $80 \%$ \\
\hline Solving arithmetic, logic and relational expressions & $90 \%$ \\
\hline Use of the counter and accumulator variable & $60 \%$ \\
\hline Selection structure & $100 \%$ \\
\hline Repetition structure & $80 \%$ \\
\hline Algorithm creation and definition & $\begin{array}{l}\text { Yes - } 100 \% \\
\text { No - } 0 \%\end{array}$ \\
\hline $\begin{array}{l}\text { Did the learning environment was appropriate to develop the course } \\
\text { competences? }\end{array}$ & $\begin{array}{l}\text { Yes - } 100 \% \\
\text { No - } 0 \%\end{array}$ \\
\hline $\begin{array}{l}\text { Do you think that evaluating your skills at the beginning of the four- } \\
\text { month period was the right activity to do in order to determine the best } \\
\text { learning environment? }\end{array}$ & $\begin{array}{l}\text { Total approval. The students said they were motivated to } \\
\text { investigate and learn more autonomously. }\end{array}$ \\
\hline $\begin{array}{l}\text { What suggestion do you have for future classes regarding the way to } \\
\text { learn the course content? }\end{array}$ & \\
\hline
\end{tabular}

2. Offer a basic training about the use of the platform Moodle, and guarantee its availability. Explain in detail the different contents and activities that are available for the students in order to learn the course concepts.

3. Explain the learning scenarios to the whole experimental group. Emphasize the importance of the checklists in relation to the evaluative assignments selected by the student.

4. Individually, indicate the learning scenario that corresponds to the student after having taken the computational thinking evaluation. This has to be done one by one in order to avoid group influence in their personal decision, but without being inflexible. The final choice is made by the student who also will set delivery times and define their learning pace.

5. It is highly recommended to conduct the midterm survey in order to know about of the students' experience regarding their learning environment, and make the necessary adjustments for improving the academic, emotional, and social results (student-group).

6. Develop new content and exercises with different levels of difficulty that are optional for the student based on their performance in the platform Moodle.

7. Carry out the final survey to detect improvement opportunities in the platform content and hopefully reassure the educational strategy acceptance. 


\section{CONCLUSION}

A well-grounded personalized education proposal was created that mainly offered initial learning scenarios as a way to study the Programming Methodology course for new students. It also provided a variety of study materials, workspaces, flexibility in pace and learning times and evaluation options. The proposed strategy also involved a relationship between computational thinking skills and the course topics. Consequently, based on the evaluation of computational thinking the student was provided with some learning scenarios options. The proposed scenarios are work plans that tackle specific skills given that the student had an incorrect answer that evaluated that particular skill. For example, if he or she answered incorrectly the exercise that evaluates the Breakdown ability, which partially belongs to the thematic Unit 1 about Concepts and to the scenario 9, then we propose to the student to work on the corresponding topics and encourage autonomous learning, without failing to provide the benefits of the face-to-face environment.

Personalized education in Higher Education has many opportunities to offer to the students, but the teacher sometimes has work overload due to the high number of students enrolled in university courses, mainly in the first years, where the groups are large. With the interventions performed the educational experience of the new students was improved, highlighting the ability to adapt to the individuality of the participants using Information Technologies. In addition, the pass rate, grade and dropout indicators were maintained with the proposal. Therefore, considering personalized education for teaching computer programming goes beyond getting students to use a given programming language and coding programs. Personalized education is also associated with the creation of a learning methodology that may be different for each student, and will reinforce a personal style for software development.

\section{REFERENCES}

Barba, E., \& Chancellor, S. (2015) Tangible media approaches to introductory computer science. Annual Conference on Innovation and Technology in Computer Science Education, 207-212. doi: $10.1145 / 2729094.2742612$

Berlanga, A. J., \& García-Peñalvo, F. J. (2005a). IMS LD reusable elements for adaptive learning designs. Journal of Interactive Media in Education, 11.

Berlanga, A. J., \& García-Peñalvo, F. J. (2005b). Learning Technology Specifications: Semantic Objects for Adaptive Learning Environments. International Journal of Learning Technology, 1(4), 458-472. doi:10.1504/IJLT.2005.007155

Berlanga, A. J., \& García-Peñalvo, F. J. (2008). Learning Design in Adaptive Educational Hypermedia Systems. Journal of Universal Computer Science, 14(22), 3627-3647. doi:10.3217/jucs-014-22-3627

Bernardo, J., Javaloyes, J. J., \& Calderero, J. F. (2011). Educación personalizada: principios, técnicas y recursos. Madríd: Síntesis.

Calderero, J. F., Aguirre, A. M., Castellanos, A., Peris, R. M., \& Perochena, P. (2014). Una nueva aproximación al concepto de educación personalizada y su relación con las TIC. Education in the Knowledge Society, 15(2), 131-151. 
Chrysafiadi, K., \& Virvou, M. (2015). A novel hybrid student model for personalized education. Intelligent Systems Reference Library, 78, 61-90. doi:10.1007/978-3-319-12895-5_3

Echegaray, G., Barroso, N., Laskurain, I., Zuza, K., \& Barragués, J. I. (2017). Investigación cualitativa para la mejora de los resultados académicos en primer curso en los grados de Ingeniería de la Escuela de Ingeniería de Gipuzkoa. IV Congreso Internacional sobre Aprendizaje, Innovación y CompetitividadCINAIC. 10.26754/CINAIC.2017.000001_093

Gao, P. (2014). Using Personalized Education to take the place of Standardized Education. Journal of Education and Training Studies, 2(2), 44-47. doi:10.11114/jets.v2i2.269

Hart, S. A. (2016). Precision Education Initiative: Moving Toward Personalized Education. Mind, Brain and Education: the Official Journal of the International Mind, Brain, and Education Society, 10(4), 209-211. doi:10.1111/mbe.12109 PMID:28642807

Humanante, P. R., García-Peñalvo, F. J., \& Conde, M. A. (2015). Mobile personal learning environments: conceptualization and structure. 3rd International Conference in Technological Ecosystems for Enhancing Multiculturality (TEEM 2015), Porto, Portugal.

Kostolányová, K. (2017). Adaptation of personalized education in e-learning environment. Lecture Notes in Computer Science, 10108, 433-442. doi:10.1007/978-3-319-52836-6_46

Kucirkova, N., \& Littleton, K. (2017). Developing personalised education for personal mobile technologies with the pluralisation agenda. Oxford Review of Education, 43(3), 276-288. doi:10.1080/030549 85.2017.1305046

Laksitowening, K. A., \& Hasibuan, Z. A. (2015). Personalized e-learning architecture in standard-based education. Proceedings - 2015 International Conference on Science in Information Technology: Big Data Spectrum for Future Information Economy, 110-114. 10.1109/ICSITech.2015.7407787

Lerís, D., \& Sein-Echaluce, M. L. (2011). La personalización del aprendizaje: Un objetivo del paradigma educativo centrado en el aprendizaje. Arbor, 187(Extra_3), 123-134. doi:doi:. doi:10.3989/arbor.2011. Extra-3n3135

Morrowy, T., Sarvestaniz, S. S., \& Hursony, A. R. (2016). Algorithmic decision support for personalized education. Proceedings - 2016 IEEE 17th International Conference on Information Reuse and Integration, 188-197. doi: 10.1109/IRI.2016.32

Prieto Ferraro, M., Leighton Álvarez, H., \& García-Peñalvo, F. J. (2004). Adaptive Educational Hypermedia Proposal Based on Learning Styles and Quality Evaluation. In P. De Bra \& W. Nejdl (Eds.), Adaptive Hypermedia and Adaptive Web-Based Systems. 3rd International Conference, AH 2004, Proceedings (pp. 316-319). Berlin: Springer Verlag.

Sadovaya, V. V., Korshunova, O. V., \& Nauruzbay, Z. Z. (2016). Personalized education strategies. Mathematics Education, 11(1), 199-209. doi:10.12973/iser.2016.21019a

Secretaría de Educación Pública. (2017). Ruta para la implementación del modelo educativo. SEP-México. 
Sun, N., Li, K., \& Zhu, X. (2016). Action research on visualization learning of mathematical concepts under personalized education idea: Take learning of geometrical concepts of elementary math for example. Lecture Notes in Computer Science, 9757, 348-359. doi:10.1007/978-3-319-41165-1_31

Tejeda-Lorente, A., Bernabé-Moreno, J., Porcel, C., Galindo-Moreno, P., \& Herrera-Viedma, E. A. (2015). Dynamic recommender system as reinforcement for personalized education by a fuzzly linguistic web system. Procedia Computer Science, 55, 1143-1150. doi:10.1016/j.procs.2015.07.084

Tekin, C., Braun, J., \& Van Der Schaar, M. (2015). eTutor: Online learning for personalized education. ICASSP, IEEE International Conference on Acoustics, Speech and Signal Processing - Proceedings, 5545-5549. doi: 10.1109/ICASSP.2015.7179032

Villegas-Ch, W., \& Luján-Mora, S. (2017). Analysis of data mining techniques applied to LMS for personalized education. EDUNINE 2017 - IEEE World Engineering Education Conference: Engineering Education - Balancing Generalist and Specialist Formation in Technological Carriers: A Current Challenge, Proceedings, 85-89. 10.1109/EDUNINE.2017.7918188

Virvou, M. (2015). Student modeling for personalized education: A review of the literature. Intelligent Systems Reference Library, 78. doi:10.1007/978-3-319-12895-5_1

Zhao, F.-Q. (2016). Personalized Education Approaches for Chemical Engineering and Relevant Majors. MATEC Web of Conferences, 68. 10.1051/matecconf/20166820003

\section{KEY TERMS AND DEFINITIONS}

Abstraction: Ability to decide which details of a problem are important and which details can be omitted.

Algorithmic Design: Ability to create a set of instructions that indicate step by step the solution of a problem for a device.

B-Learning: Learning environment that combines face-to-face instruction with teaching through information and communication technologies.

Computational Thinking: Cognitive process that allows the generation of solutions to problems through the use of specific skills, such as abstraction, decomposition, generalization, evaluation, and algorithmic design.

Computer Programming: Creation of software for the resolution of problems or activities of recreation of the industry or personal use through the use of a computer.

Decomposition: Fragment to smaller pieces, easy to solve, parts of a problem.

Evaluation: Ability to recognize and determine the scope of processes, in terms of efficiency and use of resources.

Generalization: Ability to express the solution of a problem in generic terms, which can be applied to different problems that share some of the same characteristics as the original problem.

Methodology of Programming: Set of knowledge and strategies for the creation of software. 
Personalized Education for a Programming Course in Higher Education

Personalized Education: Educational conception that recognizes the individuality of learning, understanding that each student is unique as a person and learns at different ways and rates, whether in a classroom or online environment.

Software: Set of instructions that run on a computer to perform a specific activity. 